\title{
Efeito da endogamia sobre a sobrevivência e a longevidade no escargot da espécie Helix aspersa
}

[Effect of inbreeding on viability and longevity of edible snail Helix aspersa]

\author{
E.D.R. Soares ${ }^{1}$, H.D. Silva ${ }^{2}$, J.L.A. Armada ${ }^{2}$, G.R. Leitão ${ }^{2}$, M.B. Pereira ${ }^{2}$ \\ ${ }^{1}$ Escola Agrotécnica Federal de Unataí - UNED - Mourinhos, GO \\ ${ }^{2}$ Departamento de Genética - UFRRJ \\ Rodovia BR 465, $\mathrm{km} 7$ \\ 23890-000 - Seropédica, RJ
}

\begin{abstract}
RESUMO
Estudou-se o efeito da endogamia sobre as características sobrevivência (intervalos de 0-30; 30-60; 60-90 e 90-120 dias) e longevidade do escargot da espécie Helix aspersa em três gerações consecutivas de acasalamentos entre irmãos perfeitos. Os animais foram criados em laboratório com temperatura entre 20 e $25^{\circ} \mathrm{C}$ e umidade relativa entre 70 a $90 \%$. O menor percentual de sobrevivência ocorreu no primeiro intervalo, mas, com o aumento da endogamia, observou-se diminuição na sobrevivência nos quatro intervalos testados. A longevidade média foi de 314 e 306 dias para as gerações um e três, respectivamente, não tendo sido observados animais em hibernação. O estudo de simulação para o caráter sobrevivência, em função do coeficiente de endogamia, indicou que se deve iniciar uma criação com, pelo menos, 100 reprodutores não aparentados.
\end{abstract}

Palavras-chave: Helix aspersa, escargot, endogamia, longevidade e sobrevivência

\begin{abstract}
The effect of inbreeding on longevity and viability (intervals of 0-30, 30-60, 60-90, and 90-120 days of birth) in three consecutive generations of full sibs of escargot Helix aspersa raised under laboratory conditions (20-25 C temperature; $70-90 \%$ relative humidity) was studied. Inbreeding effects decreased the viability for all the studied intervals. The longevity means were 314 and 306 days, respectively to the first and third generations. Hibernating animals were not observed. Population size of at least 100 nonrelated mating escargots replaced after 10 generations to avoid inbreeding effect is recommended.
\end{abstract}

Keywords: Helix aspersa, edible snail, inbreeding, viability, lifespan

\section{INTRODUÇÃO}

Estudos sobre a helicicultura são escassos no Brasil, principalmente quanto ao melhoramento genético com a finalidade de obterem-se estirpes mais adaptadas às condições ambientais brasileiras e de maior valor produtivo e reprodutivo.

Albuquerque de Matos e Serra (1984), Albuquerque de Matos (1989) e Soares et al. (2003), ao trabalharem com Helix aspersa,

Recebido em 10 de dezembro de 2009

Aceito em 14 de junho de 2010

*Autor para correspondência (corresponding author)

E-mail: armada@ufrrj.br afirmaram que os acasalamentos endogâmicos produzem efeitos deletérios sobre diversas características de importância econômica. Lazaridou-Dimitriadou et al. (1998) mostraram que problemas decorrentes da endogamia influenciavam no diâmetro final da concha, do peso, da maturidade, da fecundidade e da mortalidade.

De acordo com Lazaridou-Dimitriadou e Saunders (1986), na Europa, a longevidade de escargots criados na natureza é de quatro a cinco anos de idade. No Brasil, não há esse tipo de informação, pois as criações são domésticas. 
Este trabalho teve como objetivos estudar o efeito da endogamia sobre a sobrevivência e a longevidade em uma população de escargots da espécie Helix aspersa durante três gerações sucessivas e estimar os riscos econômicos causados pela endogamia.

\section{MATERIAL E MÉTODOS}

A descrição e a metodologia utilizada neste trabalho são encontradas em Soares et al. (2003). Foram consideradas famílias de irmãos perfeitos (F), todos os descendentes de pares de animais ("casais") e geração (G), e o conjunto de descendentes das sete famílias incluídas no estudo em quatro gerações de descendentes. A característica sobrevivência foi avaliada nos intervalos 0-30, 30-60, 60-90 e 90-120 dias.

Para os percentuais de sobrevivência e longevidade, o tratamento estatístico utilizado foi a análise de variância no delineamento experimental inteiramente ao acaso, com fatorial 3 x 7 (gerações x famílias), com duas repetições. Para a característica sobrevivência, foram feitas análises de regressão linear, de acordo com o modelo matemático $\mathrm{Y}_{\mathrm{ij}}=\propto+\beta \mathrm{x}_{\mathrm{i}}+\mathrm{E}_{\mathrm{ij}}$, em que $\mathrm{Y}_{\mathrm{ij}}$ é o valor observado; $\propto$ é o coeficiente linear; $\beta$ é o coeficiente angular; $E_{i j}$ é o erro experimental.

As análises de variância e de regressão e o teste de médias foram feitos por meio do programa ESTJABOT (Sistema para análise estatística V 1.0, UNESP). Para comparação das médias, utilizou-se $\mathrm{o}$ teste Tukey com $5 \%$ de significância.

\section{RESULTADOS E DISCUSSÃO}

O percentual de sobrevivência na G1 diminuiu com o aumento da densidade populacional, mostrando que a densidade mais adequada seria a de 50 animais $/ \mathrm{m}^{2}$, o que contrasta com as recomendações de Jess e Marks (1995), que propuseram densidade de 100 a 200 animais $/ \mathrm{m}^{2}$. Desse modo, passou-se a utilizar a referida densidade a partir da G2. O efeito da endogamia sobre o percentual de sobrevivência, dentro de cada família $(F)$, foi significativo em F1 e F7 $(\mathrm{P}<0,01), \mathrm{F} 2, \mathrm{~F} 4$ e F6 $(\mathrm{P}<0,05)$, mas não foi observada diferença significativa em F3 e F5.
As médias e a depressão endogâmica das sete famílias em G2, G3 e G4 do caráter percentual de sobrevivência são apresentadas na Tab. 1. Observou-se redução no percentual de sobrevivência de G2 para G3, porém a depressão foi significativa $(\mathrm{P}<0,05)$ apenas em F7. Quando se comparou a média das famílias de G3 com G4, constatou-se decréscimo significativo do percentual de sobrevivência, sendo a F1 a que apresentou depressão significativa. Resultados diferentes foram obtidos quando se compararam G2 e G4, em que a depressão endogâmica foi significativa $(\mathrm{P}<0,05)$ para todas as famílias, com exceção da F5.

Diferentes graus de depressão endogâmica foram observados entre as famílias, mostrando que algumas delas, além de apresentarem genótipos superiores, podem ser homozigotas para muitos alelos favoráveis ou carregarem poucos alelos deletérios que resultaram em pouca ou nenhuma depressão endogâmica. Com relação à $\mathrm{F5}$, na qual as médias permaneceram praticamente inalteradas nas três gerações, pode ser que, nesses locos, os genes já estivessem em homozigose ou, se em heterozigose, com ausência de dominância.

O percentual médio de sobrevivência variou entre as diferentes gerações, sendo maior na $\mathrm{G} 2,82,4 \%$, e mais baixa na G4, $51,2 \%$ (Tab. 1). Lazaridou-Dimitriadou et al. (1998), ao estudarem a mortalidade, o crescimento e a fecundidade por sete gerações sucessivas, verificaram que o percentual de mortalidade variou de 0 a $10 \%$ até a geração G6, e que, a partir dessa geração, o percentual de mortalidade foi de $25 \%$, bem menor do que o obtido neste estudo, provavelmente porque os autores utilizaram, inicialmente, cinco posturas diferentes, o que certamente provocou efeito mais lento da endogamia.

A regressão da média do percentual de sobrevivência em função dos três níveis de endogamia apresentou comportamento que pode ser descrito como linearmente negativo $\left(\mathrm{R}^{2}=\right.$ 0,999). O aumento de $1 \%$ no coeficiente de endogamia diminui em $1,3 \%$ o percentual de sobrevivência, conforme a equação de regressão linear simples: $\mathrm{Y}=116,16-133,69 \mathrm{X}$. 
Tabela 1. Percentual de sobrevivência e depressão endogâmica de sete famílias de escargot Helix aspersa, segundo as gerações $(\mathrm{G})$

\begin{tabular}{cccccccc}
\multirow{2}{*}{ Família } & \multicolumn{3}{c}{ Sobrevivência, \% } & & 3 & Depressão, \% \\
\cline { 2 - 4 } \cline { 7 - 8 } & G2 & G3 & G4 & & G2/G3 & G3/G4 & G2/G4 \\
\hline F1 & 81,67 & 77,54 & 36,67 & & $5,06^{\mathrm{ns}}$ & $52,71^{*}$ & $55,10^{*}$ \\
F2 & 85,00 & 68,48 & 54,76 & & $19,44^{\mathrm{ns}}$ & $20,04^{\mathrm{ns}}$ & $35,58^{*}$ \\
F3 & 83,34 & 66,67 & 55,00 & & $20,00^{\mathrm{ns}}$ & $17,50^{\mathrm{ns}}$ & $34,01^{*}$ \\
F4 & 75,00 & 50,40 & 46,67 & & $32,80^{\mathrm{ns}}$ & $7,40^{\mathrm{ns}}$ & $37,77^{*}$ \\
F5 & 82,05 & 76,67 & 78,34 & & $6,56^{\mathrm{ns}}$ & $-2,17^{\mathrm{ns}}$ & $4,53^{\mathrm{ns}}$ \\
F6 & 86,67 & 83,33 & 58,34 & & $3,85^{\mathrm{ns}}$ & $29,99^{\mathrm{ns}}$ & $32,69^{*}$ \\
F7 & 83,33 & 43,33 & 28,33 & & $48,00^{*}$ & $34,62^{\mathrm{ns}}$ & $66,00^{*}$ \\
\hline Média & 82,44 & 66,63 & 51,16 & $19,17^{*}$ & $23,22^{*}$ & $37,94^{*}$ \\
\hline
\end{tabular}

ns = significativo; $*=5 \%$ de significância; $* *=1 \%$ de significância.

Embora o contraste de médias tenha mostrado que algumas famílias apresentavam depressão endogâmica não significativa nos dois primeiros contrastes, o coeficiente de regressão em função dos níveis de endogamia mostrou comportamento linear negativo e significativo para todas as famílias, com exceção da F5. Estes resultados estão de acordo com os obtidos por Crow e Kimura (1970).

Em relação ao percentual de sobrevivência do escargot $H$. aspersa determinado nos quatro intervalos de observação em G2, G3 e G4, verificou-se diferença entre os intervalos de observação para G2 $(\mathrm{P}<0,01)$ e G3 $(\mathrm{P}<0,05)$, mas não para G4.

A comparação feita pelo teste Tukey mostrou que as médias obtidas nos intervalos observados foram semelhantes em G2, com exceção do primeiro intervalo (0-30 dias), que diferiu $(\mathrm{P}<0,05)$ dos demais. Para G3, a diferença observada ocorreu entre os intervalos 0-30 e 90120 dias, e não foram observadas diferenças nos demais contrastes. Para G4, não foram observadas diferenças entre as médias dos intervalos (Tab. 2). Assim, questiona-se por que na G4 o percentual de sobrevivência não foi menor nos 30 primeiros dias de vida, como ocorreu nas gerações anteriores. Pode ser que, em G2 e G3, poucos locos estivessem em homozigose ou que o número de genes em homozigose na G4 tenha sido maior quando comparado com o das gerações anteriores. Todavia, pode-se pensar, também, que o efeito de ambiente tenha sido mais acentuado na G4, pelo fato de os indivíduos terem mais locos em homozigose, tornando-os mais sensíveis a esse efeito. Todas essas observações sugerem que, em $H$. aspersa, o menor percentual de sobrevivência ocorre nos 30 primeiros dias de vida e que o aumento dos níveis de endogamia leva à diminuição da sobrevivência em todos os intervalos. $\mathrm{O}$ efeito da endogamia sobre a longevidade em $H$. aspersa foi estudado apenas em G1 e G3. A G2 não foi utilizada por ter sido criada em época diferente do ano e por ter ocorrido efeito significativo da endogamia sobre a longevidade.

A análise de variância do caráter longevidade das sete famílias em G1 e G3 mostrou efeito de família $(\mathrm{P}<0,05)$, enquanto os efeitos de geração e interação família $x$ geração não foram significativos. O coeficiente de variação foi de $13,7 \%$.

Tabela 2. Percentual de sobrevivência do escargot Helix aspersa determinado em quatro intervalos regulares de observação de três gerações endógamas

\begin{tabular}{cccc} 
Intervalos de observação & \multicolumn{3}{c}{ Geração } \\
\cline { 2 - 4 } (dias) & G2 & G3 & G4 \\
\hline $0-30$ & $89,89 \mathrm{~b}$ & $85,39 \mathrm{~b}$ & $82,76 \mathrm{a}$ \\
$30-60$ & $95,42 \mathrm{a}$ & $88,60 \mathrm{ab}$ & $82,12 \mathrm{a}$ \\
$60-90$ & $96,67 \mathrm{a}$ & $91,72 \mathrm{ab}$ & $83,02 \mathrm{a}$ \\
$90-120$ & $99,41 \mathrm{a}$ & $96,07 \mathrm{a}$ & $87,55 \mathrm{a}$ \\
\hline Média & $95,35 \mathrm{~A}$ & $90,45 \mathrm{~B}$ & $83,86 \mathrm{C}$ \\
\hline
\end{tabular}

Letras minúsculas diferentes (intervalos) na coluna e maiúsculas diferentes (médias entre as gerações) na linha indicam diferença significativa pelo teste Tukey a 5\% de probabilidade. 
Nas condições do experimento, a longevidade média foi, aproximadamente, 314 e 306 dias, variando de 265 a 323 e 218 a 431 dias em G1 e $\mathrm{G} 3$, respectivamente, ao invés de quatro a cinco anos de idade, como ocorre, na natureza, na Europa (Lazaridou-Dimitriadou e Saunders, 1986). Isso ocorreu, provavelmente, porque as condições experimentais resultaram em um ritmo de vida mais intenso, pois não foram observados animais em hibernação. É importante ressaltar que na natureza os animais entram em hibernação por até seis meses, quando as condições do ambiente não são favoráveis ao seu desenvolvimento, o que resulta em maior longevidade. Não foram encontrados estudos a respeito da longevidade em $H$. aspersa em condições ambientais do Brasil, porém estimativas feitas por criadores indicam um período de dois a três anos de vida para essa espécie. Além das recomendações sobre manejo reprodutivo apresentadas por Soares et al. (2003), sugere-se a densidade de 50 animais $/ \mathrm{m}^{2}$.

Fez-se uma simulação para a característica sobrevivência, supondo sete diferentes grupos de animais, cada grupo simulando um plantel, iniciado e mantido com um número fixo de animais, não aparentados e não endogâmicos. Foram simulados plantéis com 10, 30, 50, 70, 90, 100 e 110 indivíduos, com acasalamentos ao acaso dentro do grupo, durante 10 gerações sucessivas, sempre com o mesmo número de indivíduos. Os níveis de endogamia para cada grupo e gerações foram obtidos pela equação apresentada por Falconer (Falconer e McKay, 1996).

Como as médias de cada característica têm comportamento linear em relação ao coeficiente de endogamia (Falconer e Mackay, 1996), foi possível realizar as simulações para a característica sobrevivência mediante uma relação entre os coeficientes de endogamia, calculados para cada grupo de animais e os valores da depressão por endogamia. Com base nos valores obtidos pode-se afirmar que $5 \%$ de endogamia já é suficiente para causar riscos econômicos ao helicicultor. Assim, nesta simulação, verificou-se que, em criações iniciadas com 10 reprodutores, o prejuízo causado pela endogamia surge logo na primeira geração, observando-se depressão de 6,7\% para o caráter sobrevivência. Para criações iniciadas com 100 reprodutores, diminuição equivalente só é observada na $10^{\mathrm{a}}$ geração. Logo, estes resultados confirmam as recomendações feitas por Albuquerque de Matos e Serra (1984) de que o número mínimo recomendado para o início da criação é de 100 reprodutores.

\section{AGRADECIMENTOS}

Ao curso de pós-graduação em Biologia Animal da UFRRJ, pelo apoio, e à Fundação de Amparo a Pesquisa do Estado do Rio de Janeiro (FAPERJ), pela bolsa de estudo concedida ao primeiro autor.

\section{REFERÊNCIAS BIBLIOGRÁFICAS}

ALBUQUERQUE de MATOS, R.M. Contributions of genetics to snail farming and conservation. In: Slugs and snails in world agriculture. Brighton: BCPC monograph, v.41, p.11-18, 1989.

ALBUQUERQUE de MATOS, R.M.; SERRA, J.A. Taxonomic polymorphism and intrinsic factors in Helix aspersa. Brotéria Genética v.5, p.181-220, 1984.

CROW, J.F.; KIMURA, M. An introduction to population genetics theory. New York: Harper \& Row, 1970.

FALCONER, D.S.; MACKAY, T.F.C. Introduction to quantitative genetics, 4.ed. Harlow, Essex, UK: Longman, 1996

JESS, S.; MARKS, R.J. Population density effects on growth in culture of the edible snail Helix aspersa var. maxima. J. Molluscan Stud., v.61, p.313-323, 1995.

LAZARIDOU-DIMITRIADOU, M.; ALPOYANNI, E.; BAKA, M. et al. Growth, mortality and fecundity in successive generations of Helix aspersa Müller cutured indoors and crowding effects on fast-medium and slow - growing snails of the same clutch. $J$. Molluscan Stud., v.64, p.67-74, 1998.

LAZARIDOU-DIMITRIADOU, M.; SAUNDERS, D.E. The influence of humidity, photoperiod and temperature on the dormancy and activity of Helix lucorum (Gastropoda Pulmonata). J. Molluscan Stud., v.52, p.180-189, 1986.

SOARES, E.D.R.; ARMADA, J.L.A.; SILVA, H.D. et al. Efeito da endogamia sobre a maturidade sexual e fecundidade do escargot da espécie Helix aspersa. Arq. Bras. Med. Vet. Zootec., v.55, p.634-638, 2003. 